\title{
Trends in Membrane Distillation for Wastewater Treatment
}

\section{Graziela Salvan Cerveira1,2, Jorge Lima de Magalhães ${ }^{3,4}$, Adelaide Maria de S. Antunes ${ }^{1,2}$}

${ }^{1}$ Program of Engineering of Chemical and Biochemical Processes, School of Chemistry, Universidade Federal do Rio de Janeiro, Rio de Janeiro, Brazil

${ }^{2}$ Instituto Nacional da Propriedade Industrial (INPI), Rio de Janeiro, Brazil

${ }^{3}$ Professional Postgraduation Program in Management, Research and Development in the Pharmaceutical Industry, Centre for Technological Innovation/NIT-FAR, Oswaldo Cruz Foundation/FIOCRUZ, Ministry of Health, Rio de Janeiro, Brazil ${ }^{4}$ Global Health and Tropical Medicine (GHTM), Instituto de Higiene e Medicina Tropical (IHMT), University NOVA of Lisbon (UNL), Rua da Junqueira, Lisbon, Portugal

Email: grazisalvan@yahoo.com.br

How to cite this paper: Cerveira, G.S., de Magalhães, J.L. and de S. Antunes, A.M. (2021) Trends in Membrane Distillation for Wastewater Treatment. Journal of Environmental Protection, 12, 106-124. https://doi.org/10.4236/jep.2021.122008

Received: January 4, 2021

Accepted: February 21, 2021

Published: February 24, 2021

Copyright (C) 2021 by author(s) and Scientific Research Publishing Inc. This work is licensed under the Creative Commons Attribution International License (CC BY 4.0).

http://creativecommons.org/licenses/by/4.0/

\begin{abstract}
Membrane distillation (MD) is a promising technology that enables the treatment of high-salinity wastewater. To monitor the state and trends of MD technology for wastewater treatment, the patent filings from the last nine years were analyzed. A total of 72 documents with a special focus either on the membrane itself or on the equipment and process were found. China, United States and Japan play a leading role in the development of these technologies. Most of the inventions concentrating on the membrane apply polymers as the material. Inventions describing the equipment and process are mainly related to system and module design, but also cover the combination of MD with other technologies, the treatment customization to a specific type of wastewater, fouling control and cleaning, and energy recovery. Finally, enhancements in water flux and energy efficiency are found to be key factors to broaden the application of MD technology in wastewater treatment.
\end{abstract}

\section{Keywords}

Membrane Distillation, Patents, Trends, Wastewater

\section{Introduction}

Water is an essential component for life on earth and a precious resource for human civilization. Access to safe and affordable drinking water is considered one of the basic human necessities and remains one of the main challenges of the 21 st century. The current global water supply presents many challenges, as 785 
million people lack even a basic drinking-water service [1]. It is of fundamental importance to implement a clean water supply in the affected areas, especially in developing countries, where water and wastewater infrastructure are often nonexistent.

In general, water availability is limited. Water stress, resulting from water resources exploration for irrigation, domestic and industrial use, tends to aggravate in the next decades [2]. Climate change and global demand for food and energy, pushed by population growth and industrial development, are the main ingredients responsible for the deepening of the water crisis [3].

Recently, membrane distillation (MD) has gained meaningful attention as a promising technology for the production of fresh water via the treatment of highsalinity wastewater [4]. MD is a membrane-based thermally driven process, in contrast to the pressure driven membrane-based processes generally used for wastewater treatment [5]. In MD, a vapor pressure gradient is produced by a temperature differential across a hydrophobic porous membrane [6]. Vapor evaporates from the wastewater feed and diffuses through the membrane, driven by the partial pressure difference, and is then condensed in the permeate side [7]. Due to the hydrophobicity of the membrane, liquid water molecules are prevented from moving through the pores [8]. MD has many advantages in comparison to most conventional processes, such as distillation and reverse osmosis. For instance, operating temperatures are relatively low $\left(30^{\circ} \mathrm{C}-90^{\circ} \mathrm{C}\right)[6]$. Moreover, operating pressure is lower than that used in pressure-driven membrane processes like reverse osmosis [9]. Another advantage of MD is the high purity of the treated wastewater, with up to $100 \%$ retention of solid or nonvolatile contaminants on the retentate side [10]. Furthermore, the performance and the energy consumption of MD are not significantly affected by the salinity of the feed wastewater [11].

The major barriers for industry adoption of MD technology include: membrane and module design, membrane pore wetting, low permeate flux and high thermal energy demand [6] [7] [12]. Nevertheless, during the past few years, significant research has been carried out for the development of MD applied to wastewater treatment [13]-[18]. Due to this recent and expanding research, significant advances in membrane design and performance have been made and the process has become much more attractive [19].

In view of MD's potential use for removing contaminants from wastewater and for producing fresh water, it is of great interest to uncover the main challenges to the development of this technology and its future trends.

Technology foresight is a systematic process for investigating future technological developments and their interaction with the economy, society and environment. In this research, a foresight study of MD for wastewater treatment was conducted by investigating patent activity on the subject. Effectively, patent applications are important technology indicators that provide detailed information with extensive coverage worldwide. Through the collection of data from patents, 
this study aims to identify the evolution in the number of patent applications over time, the main applicant countries, the profile of the applicants, as well as to present an overview of the major technological developments. The trends in MD for wastewater treatment can represent strategic alternatives to solve global water scarcity in the future.

\section{Methodology}

The identification of the trends in MD applied to wastewater treatment involved two steps:

- Search of patent applications related to the subject; and

- Analysis of the patent applications retrieved.

The details of each step are explained as follows.

\subsection{Search of Patent Applications}

The Derwent Innovations Index was used to search for patents. It is a commercial database that covers over 39 million patent documents from 40 worldwide patent-issuing authorities in the field of chemistry, electrics, electronics, and engineering. An advanced search using keywords and the International Patent Classification (IPC) ${ }^{1}$ was performed on the Derwent Innovation Index website. The search in the database was made using the following keywords in the title/ abstract field:

- (membrane AND distillation) AND (wastewater OR wastewater OR sewage OR effluent)

The documents were also filtered by the IPC as belonging to at least one of the following groups:

- B01D-061/36: Pervaporation; Membrane distillation; Liquid permeation;

- B01D-063/00: Apparatus in general for separation processes using semipermeable membranes;

- B01D-069/00: Semi-permeable membranes for separation processes or apparatus characterized by their form, structure or properties; Manufacturing processes specially adapted therefor;

- B01D-071/00: Semi-permeable membranes for separation processes or apparatus characterized by the material; Manufacturing processes specially adapted therefor.

The objective of this search strategy was to restrict the research only to documents that involved MD applied to wastewater treatment with a special focus on the membrane, apparatus, or process. As already mentioned, the documents were retrieved by considering the main keywords and the main IPC classification groups related to $\mathrm{MD}$ applied to wastewater treatment, in order to select the most suitable documents for the study. The limitations of the search are mostly

${ }^{1}$ The IPC is the international classification system created by the Strasbourg Agreement (1971) which divides technological areas in classes from A to H. Within each class, there are subclasses, main groups and groups in a hierarchical system, with classification for the technological contents of the patents. 
related to documents that were either not comprised in the Derwent Innovations Index or did not receive any of the chosen IPC classifications. The patent search included documents indexed in the database in the 2011-2019 period. A total of 95 patent applications were found and were imported into an Excel spreadsheet. As patent applications are often filed in more than one country, constituting a patent family that shares the same priority application, it is important to mention that, in this work, patents with the same priority were counted only once.

\subsection{Analysis of the Patent Applications}

The 95 patent applications retrieved from the search were read and checked. After removing nonrelevant documents, a total of 72 that concerned MD applied to wastewater treatment remained. This number of patent applications is expressive and representative for this study, considering that MD is a new technology and is not yet applied in industrial scale.

The trends presented in this study are based on the contents of the 72 relevant patent documents that resulted from the search. The analysis led to the identification of the evolution in the number of patent applications over time, the main applicant countries and the profile of the applicants. Furthermore, the documents were manually and carefully reviewed, being divided into two categories: "Membrane" and "Equipment and process". For those pertaining to the "Membrane" category, information about membrane material, structure and properties was evaluated. For the ones pertaining to the "Equipment and process" category, the type of wastewater and the industry sector were identified, when mentioned, as well as the focus of the invention.

\section{Results and Discussion}

As noted in Chapter 2, the following categories were used to classify the 72 analyzed patent documents:

- "Membrane": includes technologies related to the membrane material, structure, and properties.

- "Equipment and process": covers technical information on MD apparatus and process design.

Figure 1 shows the distribution of the documents into these categories. A total of 32 documents (44\%) are related to the "Membrane" category, while the remaining 40 documents (56\%) belong to the "Equipment and process" category.

Figure 2 shows the evolution of patent documents published on the subject in the 2011-2019 period. The number of patent applications published each year varied from a minimum of 5 (in 2012) to a maximum of 11 (in 2018), with an average of 8 documents being published per year. The consistent number of patent documents published in recent years suggests that research on MD has been constantly carried out and shows its relevance for wastewater treatment.

According to the country or organization of priority, China (CN), United 


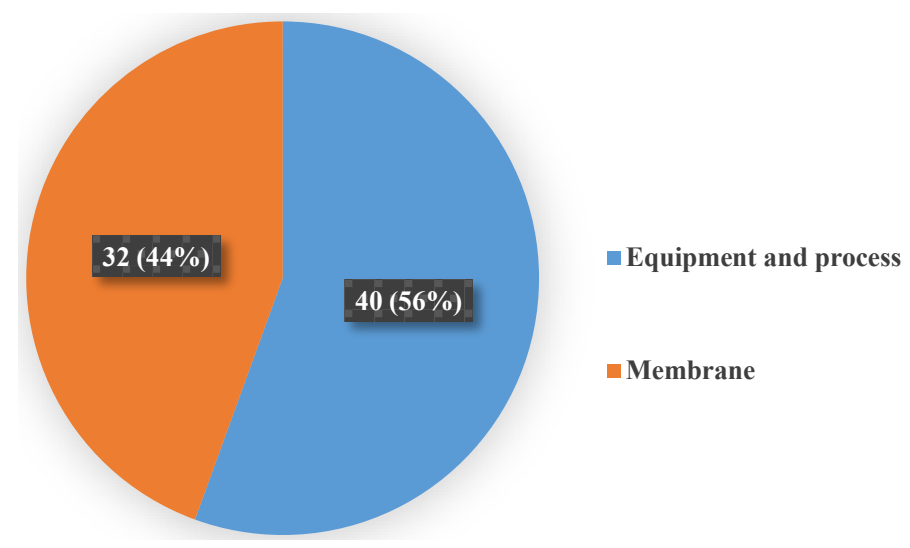

Figure 1. Number (percentage) of patent documents related to MD applied to wastewater treatment distributed between the "Membrane" and "Equipment and process" categories, retrieved from the Derwent Innovations Index database, indexed between 2011 and 2019 (own research).

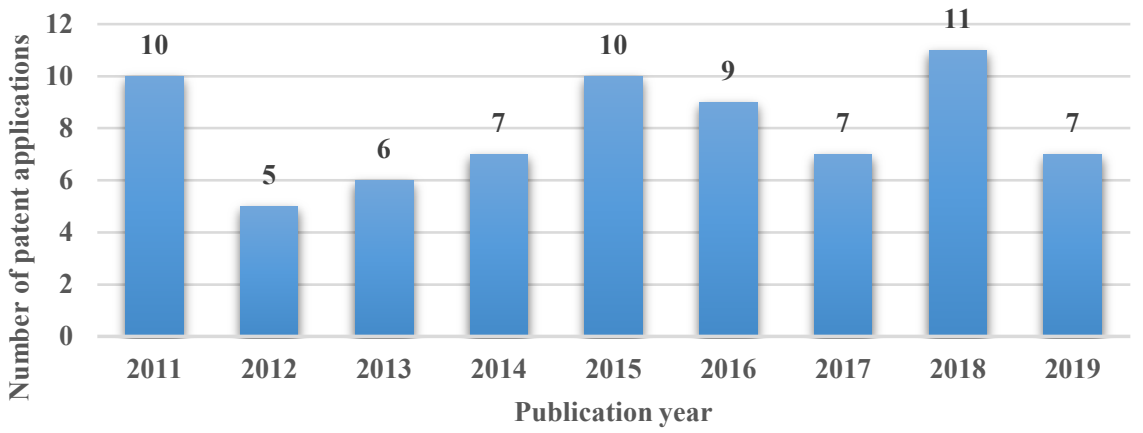

Figure 2. Evolution over time of patent applications published on MD applied to wastewater treatment, retrieved from the Derwent Innovations Index database, indexed between 2011 and 2019 (own research).

States (US) and Japan (JP) are the top three countries, making up 75\% of the patent documents retrieved (Figure 3). China has 24 patent documents alone, while the United States and Japan have 20 and 10, respectively. The country of priority is usually where the technology was developed, indicating that these three countries play a leading role in the field.

Companies are the most important type of applicant in the period of search, accounting for 39 documents which represent $54 \%$ of the total. It is worth noting that 10 companies have filed more than one patent application during the analyzed period.The profile of the patent applicants is presented in Figure 4. The name of these companies, the country of origin and the number of patent applications are specified in Table 1. The Japanese company Sumitomo Electric Ind Ltd stands out with 5 patent applications, followed by the Chinese company China Petroleum \& Chem Corp (also known as Sinopec) and by the Saudi Arabian company Sabic Global Technologies B. V., with 4 patent applications each. Table 1 also shows that Japan, United States and China are the country's most frequently chosen by main companies for filing the patent's priority applications. 


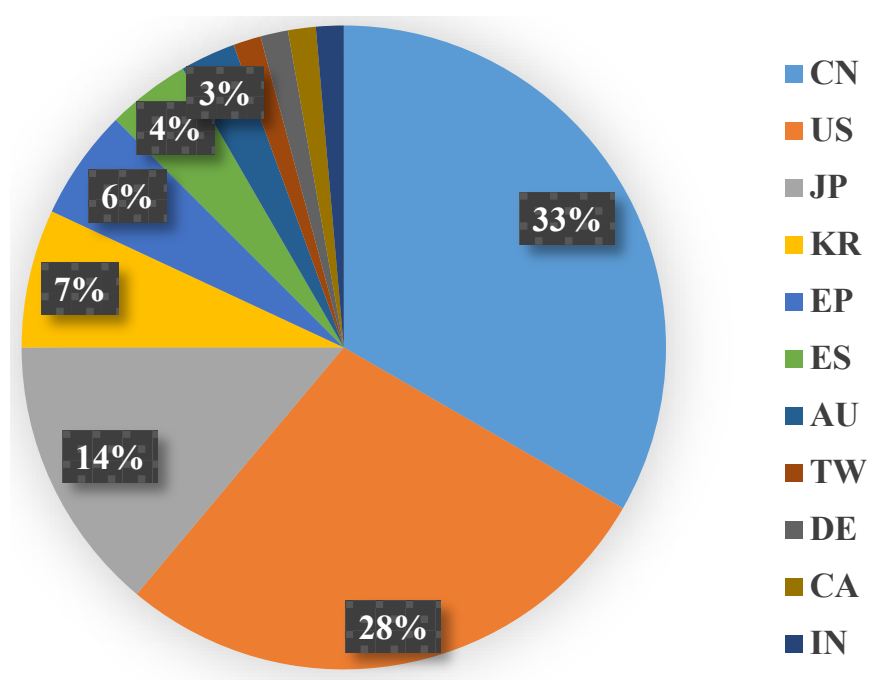

Figure 3. Distribution of patent applications about MD applied to wastewater treatment per country of origin, retrieved from the Derwent Innovations Index database, indexed between 2011 and 2019 (own research). Country codes: AU (Australia); CA (Canada); CN (China); DE (Germany); EP (European Patent Office); ES (Spain); IN (India); JP (Japan); KR (Korea); TW (Chinese Taipei); US (United States).

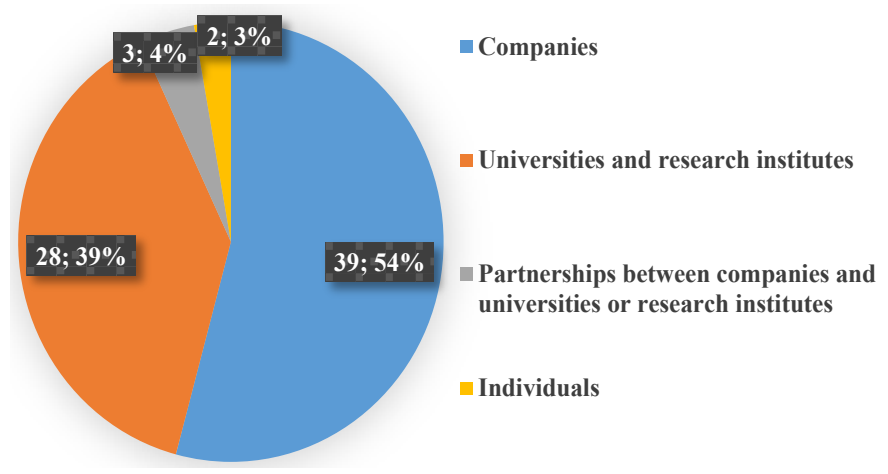

Figure 4. Profile of the patent applicants in the field of MD applied to wastewater treatment, retrieved from the Derwent Innovations Index database, indexed between 2011 and 2019 (own research).

Universities and research institutes are the second most important type of applicant, having filed 28 applications (39\% of the total). The two most important contributors for these 28 documents are China (13) and United States (7). Three institutions have filed 2 patents each during the analyzed period: Zhejiang SciTech University (China), King Abdullah University of Science and Technology (Saudi Arabia) and Netherlands Organization for Applied Scientific Research (Netherlands). Furthermore, partnerships between companies and universities or research institutes have originated only 3 patent applications, corresponding to $4 \%$ of the retrieved documents. Therefore, a significant cooperation between companies and universities in the research field of MD applied wastewater treatment has not been observed. 
Table 1. Main company applicants, country of origin and number of patent applications.

\begin{tabular}{ccc}
\hline Company Name & $\begin{array}{c}\text { Country of origin of } \\
\text { the patent applications }\end{array}$ & $\begin{array}{c}\text { Number of patent } \\
\text { applications }\end{array}$ \\
\hline Sumitomo Electric Ind Ltd & Japan & 5 \\
China Petroleum \& Chem Corp & China & 4 \\
Sabic Global Technologies B. V. & United States & 4 \\
Asahi Kasei Corp & Japan & 3 \\
Abengoa Water Sl & Spain & 2 \\
Beijing Zhongkeruisheng Resources Enviro & China & 2 \\
General Electric Co & China and United States & 2 \\
Membrane Distillation Desalination Co Ltd & China and Canada & 2 \\
Milton Roy Co & United States & 2 \\
Toray Chem Korea Inc & Korea & 2 \\
\hline
\end{tabular}

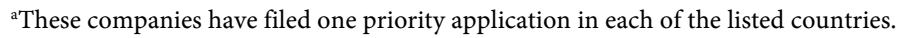

\subsection{Analysis of Patent Filings on "Membrane"}

Hydrophobicity is an essential requirement for MD membranes, because it prevents the feed liquid from entering membrane pores due to the surface tension. Therefore, this feature has to be considered when choosing the membrane material and designing its production process. The membranes must be made from intrinsic or modified hydrophobic materials. Hydrophobic polymers are the most common choice for the MD membrane material due to their characteristics of easy fabrication, modification, and scale-up, as well as low costs.

The reduction of fouling and scaling is also of significant importance in the field of wastewater treatment, due to the variety of contaminants that might be present, depending on the nature of the wastewater to be treated. To address this problem, composite polymeric membranes, membranes combining polymeric and inorganic materials, and purely inorganic membranes have been proposed as an alternative to the traditional hydrophobic polymeric membranes.

This study identified that polymeric materials are more frequently used than inorganic materials in MD applied to wastewater treatment. The examination of the 32 documents on "Membrane" showed that 22 patent documents use polymeric materials, 6 documents employ a membrane containing both polymeric and inorganic materials, and 4 documents apply purely inorganic membranes. More details on the documents are presented below.

\subsubsection{Polymeric Membranes}

Hydrophobic microporous polymeric membranes appear often in the analyzed patent documents, the most commonly cited polymers being: polytetrafluoroethylene (PTFE), polypropylene (PP) and polyvinylidene fluoride (PVDF). Membrane geometry is usually hollow fiber or flat sheet. Some examples of membrane material and geometry are presented in Table 2. 
Table 2. Examples of patent documents related to hydrophobic microporous polymeric mem-branes, their material and geometry.

\begin{tabular}{ccc}
\hline Polymer & Geometry & Patent numbers - References \\
\hline \multirow{2}{*}{ PTFE } & Hollow fiber & CN102941025 [20] \\
& & CN103386261 [21] \\
PP & Hollow fiber & CN103785303 [22] \\
& & CN104511247 [23] \\
PVDF & Hollow fiber & CN108993173 [24] \\
& Flat sheet & WO2011117443 [25] \\
\hline
\end{tabular}

Most of the documents shown in Table 2 are related to hollow fiber membranes, which have been prepared by spinning, while the flat sheet membrane has been produced by means of electrospinning. According to the inventors, this process generates a nanostructured membrane which has high permeate flow and allows a considerable reduction in heat loss due to conduction.

A significant number of patent documents employing polymers are about composite membranes (7 out of 22 documents). For instance, WO2012100318 [26] and US2011031100 [27] describe a composite membrane containing hydrophilic and hydrophobic polymer layers comprising a fluorinated surface-modifying macromolecule (SMM). These kinds of composite membranes have been proposed for use in $\mathrm{MD}$ as a possible solution to obtain higher mass transfer and lower heat transfer through the membrane. In addition, omniphobic membranes have been developed to deal with high salinity produced water which usually contains surfactants. These surface-modified membranes have significantly increased organic fouling resistance. In particular, one patent document discloses a composite membrane for distillation of a contaminated brine solution [28]. This membrane comprises an omniphobic substrate having a re-entrant structure, as well as a surface coating with a dual functional layer which is hydrophilic in air and oleophobic in water, allowing it to be antiwetting and antifouling in the presence of hydrophobic and amphiphilic contaminants.

\subsubsection{Membranes Combining Polymeric and Inorganic Materials}

The patent documents related to membranes combining polymeric/inorganic materials involved composite and/or mixed matrix membranes. The incorporation of additives is an effective and widely used method to design a MD membrane with desirable morphology, permeation performance, hydrophobicity or anti-fouling properties. CN103372378 [29] and CN109985536 [30] use hydrophilic/hydrophobic composite membranes comprising PVDF and an inorganic material, respectively: graphitic carbon nitride; and titanium dioxide and lithium chloride. WO2012100326 [31] describes a flat-sheet composite mixed matrix hydrophilic/hydrophobic membrane: the hydrophilic layer containing a hydrophilic polymer and inorganic nanoparticles of high thermal conductivity, and the hydrophobic layer containing a fluorinated surface-modifying macromolecule (SMM). The membrane is manufactured by a phase inversion method and is useful for 
direct contact MD. WO2014111889 [32] reveals the manufacture of a multilayered polymeric and mixed matrix membrane that involves providing a support layer, casting a hydrophilic layer on a surface of the support layer and finally casting a hydrophobic layer on the hydrophilic layer. The membrane is used in a plate-and-frame membrane module for direct contact MD. CN110152504 [33] reports the method for preparing a blended modified PVDF film: obtaining a casting solution by adding titanium dioxide, graphene and a porogen to a polar solvent, adding PVDF, and uniformly mixing; and then obtaining the blended matrix film by scraping the casting solution, solidifying in a coagulation bath, soaking and air-drying. The film is useful for vacuum MD in the field of high salinity organic wastewater.

\subsubsection{Inorganic Membranes}

When it comes to purely inorganic membranes, the applied materials are carbon nanotubes [34] [35] [36] and graphene [37]. In order to be suitable for the use in $\mathrm{MD}$, inorganic materials must be modified for improved hydrophobicity. CN107096393 [34] presents the preparation of a thermal stable and superhydrophobic ceramic-carbon nanotube composite membrane via chemical vapor deposition, using a ceramic hollow fiber membrane as a carrier. By changing preparation conditions, such as the amount of catalyst and the reaction temperature, membranes with varied structures and properties are obtained by the inventors.

\subsection{Analysis of Patent Filings on "Equipment and Process"}

The analysis of patent filings on "Equipment and process" indicate the great potential of MD technology for wastewater treatment. The careful reading of the documents enabled the identification of the type of wastewater and industry sectors that are likely to benefit from this technology. Furthermore, the inventions described in the patent applications are of significant value to identify the main challenges and future opportunities for implementation of MD.

\subsubsection{Types of Wastewater}

Out of 40 documents on "Equipment and process", 27 specify the target type of wastewater to be treated. From these, 22 documents are directed to industrial wastewater; 3 documents mention that the wastewater might be domestic or industrial; and 2 documents refer solely to domestic wastewater. These results imply that MD is prone to be applied for industrial wastewater treatment, rather than for domestic wastewater treatment.

The documents cover a wide range of industry sectors. The petroleum and petrochemical industry are mentioned in a considerable number of documents [38] [39] [40]. Some are directed to sources of oily wastewater, including petroleum refining, metals manufacturing, and food processing [41]. WO2017140927

[42] mentions the pharmaceutical and textile industries as possible sectors. JP2018083189 [43] and JP2019048257 [44] name wastewater from food, chemi- 
cal, electronic, pharmaceutical and cleaning industries. As expected, many of the documents have a special focus on saline wastewater, with 11 documents on "Equipment and process" citing it explicitly.

\subsubsection{Focus of the Inventions}

The information extracted from the patent documents enabled the identification of the most important topics related to "Equipment and process". Table 3 shows the documents found for each focus, as well as brief examples of their contents.

A great number of patent documents concern constructive features of the equipment, usually proposing new membrane modules and system designs with the aim of improving process efficiency. EP2283988 [50] claims a method for preparing a planar membrane module. US2011284444 [55] discloses a condensing tube applied in an air-gap MD module to not only support the membrane but also provide the selection of different air gap thicknesses, in order to increase the permeate flux by adjusting variable parameters. WO2016006670 [59] and JP2018083189 [43] describe compact MD apparatus with high water treatment capacity. CN108622983 [38] and US2011180383 [53] propose assemblies that improve heat efficiency in a MD process. CN108067100 [46] develops a spiral-wound membrane distilling device obtained by coupling a hydrophobic and a condensing membrane. US2016310900 [57] reveals membrane modules submerged in a feed solution tank. WO2017140927 [42] and JP2019048257 [44] apply for new hollow-fiber membrane module designs.

Another important aim of the inventions is to propose a combination of technologies. US2012132588 [41] describes a method and system for treating oily wastewater. The oily wastewater is pretreated using at least one of electrocoagulation, flotation or absorption; and then treated using MD. JP2014188468 [63] combines $\mathrm{MD}$, reverse osmosis and catalyst oxidation to provide a water treatment system for space applications. WO2015162314 [66] performs a pretreatment before $\mathrm{MD}$, in order to eliminate calcium hardness in waste brine from desalination plants. Calcium hardness is eliminated by a chemical treatment followed by decantation or filtration. WO2016135701 [67] discloses an integrated forward osmosis-membrane distillation module for water treatment applications. The module utilizes an isolation barrier which leads to higher efficiency of the forward osmosis and membrane distillation processes by enhancing their respective driving forces. CN106495382 [61] proposes a solution for the treatment of sweet industrial wastewater that combines filtration, incineration, nanofiltration and MD to obtain crude glycerol and water as final products.

Some documents are directed to the treatment of a specific type of wastewater, so that customized equipment and processes involving MD were presented. KR2013101279 [68] separates and recovers dimethylformamide from industrial wastewater. JP2015100775 [39] provides a solution to purify oil and salt-containing wastewater generated in a petroleum production process. KR2016149699 [69] reveals a device and method for the treatment of wastewater containing ammonia. US2017057854 [71] describes a method for treating the effluent waste from a 
Table 3. Focus of the inventions about MD applied to wastewater treatment on "Equipment and Process".

\begin{tabular}{|c|c|c|}
\hline Focus & Examples & $\begin{array}{c}\text { Patent } \\
\text { numbers-References }\end{array}$ \\
\hline $\begin{array}{l}\text { Constructive features of the } \\
\text { equipment } \\
\text { ( } 20 \text { documents) }\end{array}$ & $\begin{array}{l}\text { - improvements in system } \\
\text { - } \text { design } \\
\text { - } \text { compact MD apparatus } \\
\text { - improvements in module } \\
\text { design }\end{array}$ & $\begin{array}{l}\text { CN105692739 [45] } \\
\text { CN108067100 [46] } \\
\text { CN108619913 [38] } \\
\text { CN204261564 [47] } \\
\text { CN209065483 [48] } \\
\text { DE102012017860[49] } \\
\text { EP2283988 [50] } \\
\text { EP2606953 [51] } \\
\text { JP2014004497[52] } \\
\text { JP2018083189 [43] } \\
\text { JP2019048257 [44], } \\
\text { US2011180383 [53] } \\
\text { US2011180479 [54] } \\
\text { US2011284444 [55] } \\
\text { US2014263061 [56] } \\
\text { US2016310900 [57] } \\
\text { US2019144309[58] } \\
\text { WO2016006670[59] } \\
\text { WO2016172539[60] } \\
\text { WO2017140927 [42] }\end{array}$ \\
\hline $\begin{array}{l}\text { Combination of technologies } \\
\text { (8 documents) }\end{array}$ & $\begin{array}{l}\text { - } \begin{array}{l}\text { electrocoagulation, flotation } \\
\text { or absorption }\end{array} \\
\text { - } \text { reverse osmosis and catalyst } \\
\text { oxidation } \\
\text { - filtration, incineration, } \\
\text { nanofiltration } \\
\text { - forward osmosis }\end{array}$ & $\begin{array}{l}\text { CN106495382 [61] } \\
\text { EP2671845[62] } \\
\text { JP2014188468[63] } \\
\text { KR2016123822[64] } \\
\text { US2012048803[65] } \\
\text { US2012132588[41] } \\
\text { WO2015162314[66] } \\
\text { WO2016135701[67] }\end{array}$ \\
\hline $\begin{array}{l}\text { Customized equip./process for } \\
\text { specific wastewater types } \\
\text { ( } 6 \text { documents) }\end{array}$ & 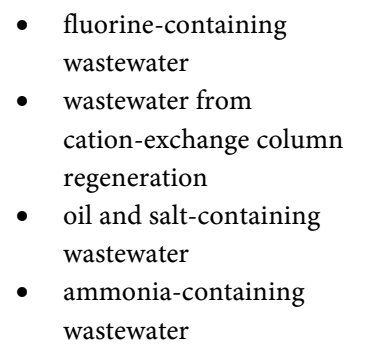 & $\begin{array}{l}\text { KR2013101279 [68] } \\
\text { KR2016149699[69] } \\
\text { JP2015100775[39] } \\
\text { JP2015100776 [40] } \\
\text { JP2018065101 [70] } \\
\text { US2017057854[71] }\end{array}$ \\
\hline $\begin{array}{l}\text { Fouling control and cleaning } \\
\text { ( } 3 \text { documents) }\end{array}$ & $\begin{array}{l}\text { - } \quad \text { cation-sequestering method } \\
\text { X-ray excitation of } \\
\text { luminescent materials }\end{array}$ & $\begin{array}{l}\text { CN108704486 [72] } \\
\text { US2014263055[73] } \\
\text { US2016107126[74] }\end{array}$ \\
\hline $\begin{array}{l}\text { Energy recovery } \\
\text { (3 documents) }\end{array}$ & $\begin{array}{l}\text { - heat recovery system } \\
\text { - usage of solar heat energy }\end{array}$ & $\begin{array}{l}\text { CN106219855 [75] } \\
\text { CN108622983 [76] } \\
\text { JP2011167597 [77] }\end{array}$ \\
\hline
\end{tabular}

cation-exchange column regeneration cycle. JP2018065101 [70] propose a method of treating a fluorine-containing water using a hydrophobic porous membrane.

Fouling control and cleaning of membranes is also a problem of concern to 
some of the documents analyzed. US2014263055 [73] presents a cation-sequestering method to prevent membranefouling. According to the method, ethylenediaminetetraacetate ions are added to the wastewater, where they bond with the cations to form a non-scaling ionic complex. The wastewater with the ionic complex is then treated by a process like $\mathrm{MD}$ to produce pure water. The $\mathrm{pH}$ of the wastewater is subsequently reduced to release the cation from the ethylenediaminetetraacetate ions, which are afterwards reused in a closed loop. US2016107126 [74] describes a method to prevent biofouling by X-ray excitation of luminescent materials placed within the membrane modules and which are capable of emitting in the violet to ultraviolet range. CN108704486 [72] discloses a method and system for cleaning and drying the membrane in a vacuum MD process. The method improves process efficiency by directly cleaning and drying the membrane after the vacuum MD of wastewater, thus avoiding the complex assembly and disassembly of membrane components.

Energy recovery is another aspect considered by the patent applications. JP2011167597 [77] describes a MD system with a raw water tank and a heat exchange apparatus using solar energy. The system is supposedly low cost and capable of being placed even in an area with inadequate infrastructure where energy acquisition and large capital investment are difficult. CN106219855 [75] discloses a device and method for water treatment with a direct air-cooling and heat recovery unit. The main advantages claimed by the inventors are the reduction of power consumption in the air-cooling system by recycling the steam waste heat and the production of high-quality fresh water through the MD system. CN108622983 [76] presents a MD device that is coupled to a heat recovery system. The latent heat of water vapor is recovered in order to heat and maintain the temperature of the raw water.

\section{Conclusions}

$\mathrm{MD}$ is a promising technology for wastewater treatment. It is a thermally driven separation process, in which only vapor molecules are able to pass through a porous hydrophobic membrane. Despite its many attractive features, like low operating pressure and high retention of contaminants, its large-scale commercialization still faces some technical challenges, such as low water flux and energy efficiency.

This patent analysis presented an overview of patent activity in MD applied to wastewater treatment. Although MD is a new technology and is not yet applied in industrial scale, the number of patent documents found was expressive and enabled the assessment of trends in the field. Some of the main findings are highlighted below:

- A consistent number of patents on "Membrane" and "Equipment and process" have been published each year over recent years.

- China, United States and Japan play a leading role in the development of the technologies, as $75 \%$ of the patent documents analyzed were originally filed 
in one of these countries.

- More than half of the patent applications were filed by companies, demonstrating that there is commercial interest and research investment on MD applied to wastewater treatment by big corporations such as Sumitomo, Sinopec, Sabic, Asahi Kasei, General Electric and Toray.

- Most of the patent documents on "Membrane" apply polymers as the membrane material, especially hydrophobic polymers like PTFE, PP and PVDF.

- Composite membranes with special wettability have also been an important focus of research for the treatment of challenging wastewaters, such as high salinity brine and wastewater containing oils or low surface tension components.

- Patent documents on "Equipment and process" are applicable to wastewater from a variety of industry sectors like petroleum and petrochemical, pharmaceutical, textile, chemical, electronic, metals manufacturing and food processing.

- Patent documents on "Equipment and process" are mainly related to constructive features of the equipment, combination of technologies, customized equipment and process for specific wastewater types, fouling control or cleaning of membranes, and energy recovery. It is evident from the contents of the patent documents that improved process efficiency and energy consumption are very relevant concerns that need to be considered when designing membrane modules and systems.

\section{Conflicts of Interest}

The authors declare no conflicts of interest regarding the publication of this paper.

\section{References}

[1] UNICEF and WHO (2019) Progress on Household Drinking Water, Sanitation and Hygiene 2000-2017. Special Focus on Inequalities. United Nations Children's Fund (UNICEF), World Health Organization (WHO), Geneva. https://www.who.int/water sanitation health/publications/jmp-2019-full-report.pdf

[2] Vörösmarty, C.J., et al. (2000) Global Water Resources: Vulnerability from Climate Change and Population Growth. Science, 289, 284-288.

https://doi.org/10.1126/science.289.5477.284

[3] Haddeland, I., et al. (2014) Global Water Resources Affected by Human Interventions and Climate Change. Proceedings of the National Academy of Sciences, 111, 32513256. https://doi.org/10.1073/pnas.1222475110

[4] Rahman Choudhury, M., et al. (2019) Fouling and Wetting in the Membrane Distillation Driven Wastewater Reclamation Process-A Review. https://doi.org/10.1016/j.cis.2019.04.008

[5] Warsinger, D.M., et al. (2018) A Review of Polymeric Membranes and Processes for Potable Water Reuse. Progress in Polymer Science, 81, 209-237. https://doi.org/10.1016/j.progpolymsci.2018.01.004

[6] Subramani, A. and Jacangelo, J.G. (2015) Emerging Desalination Technologies for 
Water Treatment: A Critical Review. Water Research, 75, 164-187. https://doi.org/10.1016/j.watres.2015.02.032

[7] Khayet, M. (2011) Membranes and Theoretical Modeling of Membrane Distillation: A Review. Advances in Colloid and Interface Science, 164, 56-88. https://doi.org/10.1016/j.cis.2010.09.005

[8] Panagopoulos, A., Haralambous, K.J. and Loizidou, M. (2019) Desalination Brine Disposal Methods and Treatment Technologies: A Review. Science of the Total Environment, 693, Article ID: 133545. https://doi.org/10.1016/j.scitotenv.2019.07.351

[9] Alkhudhiri, A., Darwish, N. and Hilal, N. (2012) Membrane Distillation: A Comprehensive Review. Desalination, 287, 2-18. https://doi.org/10.1016/j.desal.2011.08.027

[10] Drioli, E., Ali, A. and Macedonio, F. (2015) Membrane Distillation: Recent Developments and Perspectives. Desalination, 356, 56-84. https://doi.org/10.1016/j.desal.2014.10.028

[11] Wang, P. and Chung, T.S. (2015) Recent Advances in Membrane Distillation Processes: Membrane Development, Configuration Design and Application Exploring. Journal of Membrane Science, 474, 39-56. https://doi.org/10.1016/j.memsci.2014.09.016

[12] Tijing, L.D., et al. (2015) Fouling and Its Control in Membrane Distillation: A Review. Journal of Membrane Science, 475, 215-244. https://doi.org/10.1016/j.memsci.2014.09.042

[13] Qu, D., et al. (2013) Experimental Study of Ammonia Removal from Water by Modified Direct Contact Membrane Distillation. Desalination, 326, 135-140. https://doi.org/10.1016/j.desal.2013.07.021

[14] Jacob, P., et al. (2015) Direct Contact Membrane Distillation for Anaerobic Effluent Treatment. Journal of Membrane Science, 475, 330-339. https://doi.org/10.1016/j.memsci.2014.10.021

[15] Li, C., et al. (2019) Membrane Distillation Coupled with a Novel Two-Stage Pretreatment Process for Petrochemical Wastewater Treatment and Reuse. Separation and Purification Technology, 224, 23-32. https://doi.org/10.1016/j.seppur.2019.05.007

[16] Gryta, M. (2020) Separation of Saline Oily Wastewater by Membrane Distillation. Chemical Papers, 74, 2277-2286. https://doi.org/10.1007/s11696-020-01071-y

[17] Abdelkader, S., et al. (2019) Application of Direct Contact Membrane Distillation for Saline Dairy Effluent Treatment: Performance and Fouling Analysis. Environmental Science and Pollution Research, 26, 18979-18992. https://doi.org/10.1007/s11356-018-2475-3

[18] Guo, J., et al. (2020) Elucidating the Fouling Mechanism in Pharmaceutical Wastewater Treatment by Membrane Distillation. Desalination, 475, Article ID: 114148. https://doi.org/10.1016/j.desal.2019.114148

[19] Yao, M., et al. (2020) A Review of Membrane Wettability for the Treatment of Saline Water Deploying Membrane Distillation. Desalination, 479, Article ID: 114312. https://doi.org/10.1016/j.desal.2020.114312

[20] Wang, F., et al. (2013) Method for Preparing PTFE Hollow Fiber Membrane That Is Utilized in Membrane Distillation, Involves Mixing PTFE Dispersion Powder and Extruding-Aid Agent, Pressing and Extruding Blank into PTFE Hollow Tube by Pushing and Pressing Machine. CN102941025-A.

[21] Chen, J., et al. (2013) Super-Hydrophobic PTFE Hollow Fibrous Membrane Prepa- 
ration Method, Involves Selecting PTFE Disperse Resin Powder and Extrusion Aid, Mixing PTFE Disperse Resin Powder and Extrusion Aid, and Standing Mixed Product at Specific Temperature. CN103386261-A.

[22] Xi, Z., Yang, Y. and Zhang, X. (2014) Preparing Hydrophobic Polypropylene Hollow Fiber Membrane Used in Petrochemical Enterprises for Reverse Osmosis Treatment of Concentrated Water, Involves Adding Polypropylene Resin, Diluting Agent and Additive. CN103785303-A.

[23] Xi, Z., Yang, Y. and Zhang, X. (2015) Hydrophobic Polypropylene Hollow Fiber Membrane Used for Internal-Pressure Vacuum Distillation Process in Petrochemical Industry, Comprises Specified Amount of Polypropylene Resin, Diluents and Additives. CN104511247-A.

[24] Hu, B. and Jiang, L. (2018) Preparation of Polyvinylidene Fluoride (PVDF) Hollow Fiber Membrane for Distillation of Acid Wastewater, Involves Spraying Casting Liquid, and Core Liquid into Phase Change Type in Outer Condensate, to Obtain Membrane Filament, and Washing. CN108993173-A.

[25] KhayetSouhaimi, M. and Garcia Payo, M. D. C. (2011) Polyvinylidene Fluoride-coF6PP Copolymer or Polyvinylidene Fluoride Nanofibrous or Nanostructured Flat Membranes for e.g. Wastewater Treatment, Are Produced by Electrospinning with Solvents Having Different Affinities. WO2011117443-A1.

[26] Khayet, M., et al. (2012) Composite Hydrophilic Hydrophobic Membrane Used in Membrane Distillation System for e.g. Seawater Desalination, Food Processing Comprises Hydrophilic Polymer Layer, Hydrophobic Polymer Layer and Fluorinated Surface-Modifying Macromolecules. WO2012100318-A1.

[27] Qtaishat, M. R., Khayet, M. and Matsuura, T. (2011) Composite Hydrophilic/Hydrophobic Membrane Useful in Direct Contact Membrane Distillation System for Seawater Desalination, Comprises Hydrophilic and Hydrophobic Polymer Layers Comprising Fluorinated Surface-Modifying Macromolecule. US2011031100-A1.

[28] Lin, S., Wang, Z. and Huang, Y. (2018) Composite Membrane Used for Distillation of Contaminated Brine Solution, Comprises Omniphobic Substrate Having Re-Entrant Structure and Surface Coated with Dual Functional Layer Which Is Hydrophilic in Air and Oleophobic under Water. US2018345227-A1.

[29] Li, F. (2013) Hydrophilic/Hydrophobic Composite Film for e.g. Desalting Bitter Brackish Water, Has Hydrophilic Layer, Hydrophobic Layer and Nonwoven Fabric Supporting Layer, Where Film Is Made of Hydrophilic Layer Membrane Liquid and Dimethyl Acetamide. CN103372378-A.

[30] Chen, L., et al. (2019) Composite Membrane Useful in the Treatment of Oily Wastewater Comprises Hydrophobic Polyvinylidene Difluoride Film as Carrier, and the Graphitic Carbon Nitride Film as the Hydrophilic Layer. CN109985536-A.

[31] Almuttiri, S., et al. (2012) Membrane Distillation System Useful for Direct Contact Membrane Distillation, Comprises a Flat-Sheet Composite Mixed Matrix Hydrophilic/Hydrophobic Membrane Having at Least a Hydrophilic Layer and a Hydrophobic Layer. WO2012100326-A1.

[32] Almuttiri, S., Qtaishat, M.R. and Qtaishat Mohammed, R. (2014) Manufacture of Multilayered Polymeric and Mixed Matrix Membrane Used for Plate-and-Frame Membrane Module, Involves Providing Support Layer, Casting Hydrophilic Layer on Support Layer and Casting Hydrophobic Layer on Hydrophilic Layer. WO2014111889-A2.

[33] Yao, H., et al. (2019) Preparing Blended Modified Polyvinylidene Fluoride Film Useful for Vacuum Membrane Distillation and Recovery in High Salinity Organic 
Wastewater Comprises e.g. Adding Titanium Dioxide, Graphene, Polar Solvent, and Mixing. CN110152504-A.

[34] Dong, Y., et al. (2017) Complex Film Used in e.g. Desalination of Seawater, Comprises Spinel Hollow Fiber Ceramic Membrane as Carrier and Complex Structure of Carbon Nanotubes Completely Covering Carrier as Membrane Structure. CN107096393-A.

[35] Mitra, S. and Gethard, K. (2011) Membrane e.g. Flat Membrane, for Membrane Distillation Comprises a Membrane Including Nanocarbons in the Form of Single or Multiwalled Carbon Nanotubes, Incorporated into the Membrane Structure. US2011272354-A1.

[36] Dastgheib, S. A., et al. (2017) Carbon Nanotube Membrane for e.g. Producing Pure Water, Water Desalination, Recovering Dissolved Material and Direct Contact Membrane Distillation Comprises Substrate Which Is Coated with Carbon Nanotubes. US2017165612-A1.

[37] Seo, D. H., et al. (2018) Continuous Permeable Graphene Film Comprises at Least Two Layers of Graphene and Nanochannels or Nanopores Providing a Fluid Passage from One Face of the Film to the Other. WO2018161116-A1.

[38] Guo, Z., Zhang, X., Luan, J. and Zhang, C. (2018) Novel Air Gap Multi-Effect Membrane Distillation Device for Treating Different High-Salt Wastewater from Petrochemical Enterprises, Has Gas Water Separator Whose Lower End Outlet Is Connected to Inlet of Product Collection Tank. CN108619913-A.

[39] Yamaguchi, A. and Morita, T. (2015) Wastewater Treatment Method Involves Carrying Out Membrane Distillation of Isolated Heating Waste Water Using Hydrophobic Porous Membrane, and Collecting and Removing Oil Components and Salt Content Contained in Heating Waste Water. JP2015100775-A.

[40] Yamaguchi, A. and Morita, T. (2015) Method for Treating Waste Water Generated during Extracting Petroleum from Stratum or Bedrock Layer, Involves Carrying out Membrane Distillation Using Hydrophobic Porous Membrane, and Removing Oil Component. JP2015100776-A.

[41] Yu, X., et al. (2012) Treating Oily Wastewater Comprises Pretreating Oily Wastewater Using Electrocoagulation, Flotation or Absorbing to Produce Pretreated Water, and Treating Pretreated Water Using Membrane Distillation to Produce Product Water. US2012132588-A1.

[42] Khayet Souhaimi, M., et al. (2017) Set of Hollow Fiber Membranes Supported in Mesh Useful in Membrane Module for Membrane Distillation System to Treat and Desalinate Fluids. WO2017140927-A1.

[43] Arai, H., Osada, K. and Takezawa, H. (2018) Membrane Distillation Apparatus for Treatment of Water e.g. Industrial Water, Has Whole Distillation Unit That Is Heated at High Temperature from Temperature of Condensation Unit. JP2018083189-A.

[44] Takahashi, T. and Arai, H. (2019) Membrane Module for Membrane Distillation Apparatus, Includes Cylindrical Waste Strainer Which Is Embedded under Hollow Fiber Membrane at Vicinity of Water Outlet. JP2019048257-A.

[45] Li, X., Shi, Z. and Yang, X. (2016) Saline Waste Water Processing System Comprises Hydrophobic Film and Evaporator, Which Includes Water Inlet and Water Outlet, and the Hydrophobic Film Is Provided with Condensing Film inside Evaporator and Steam Pressurizing Device. CN105692739-A.

[46] Shi, Z., et al. (2018) Roll-Type Membrane Distillation Device of Membrane Distillation System, Has Evaporation Channels Which Are Configured to Receive Steam Generated by Evaporation of Raw Water by Heat, and to Discharge Steam from 
Outlet of Evaporation Channel. CN108067100-A.

[47] Guo, P., et al. (2015) Saline Wastewater Membrane Distillation Unit Includes PreAfter Raw Material Pump, Heat Exchanger, Liquid Storage Tank, Circulation Pump, Heating Device, Film Distillation System, Heat Exchange System and Distilled Water Collection Tank. CN204261564-U.

[48] Zhu, T., Yan, H. and Li, M. (2019) Ultrasonic Assisted Membrane Distillation Unit for Processing High Salt Water in Laboratory, Has Flow Meter That Is Connected to Cold Side Inlet of Membrane Module Whose Cold Side Water Outlet Is Connected to Cold Water Collection Tank. CN209065483-U.

[49] Vinz, P. (2014) Treatment Method for Enriching on Separating Mixture Components from Sewage Liquid Mixtures, Involves Depressurizing and Re-Introducing Permeate from Primary Channel of First Treatment Zone into Secondary Channel of Second Treatment Zone. DE102012017860-A1.

[50] Van Medevoort, J. (2011) Preparation Method for Planar Membrane Module, Involves Stacking Membrane Frames and Joining Membrane Frames Together in Gas-Tight Manner to Form Planar Membrane Module by Welding of Potting Material. EP2283988-A1.

[51] Maessen, R. T. H. and Weijdema, H. (2013) Membrane Distillation System for e.g. Water Purification, Has Membrane Distillation Module Whose Distillate Exit Is Provided with Fluid-Permeable Membrane Unit between Membrane Distillation Module and Distillate Collector Unit. EP2606953-A1.

[52] Kanazawa, S., Okuda, Y. and Katayama, K. (2014) Fresh Water Producing Apparatus Has Hydrophobic Porous Membrane Having Through-Hole That Permeates Water Vapor Generated from Treated Water in Which Water Pressure Resistance in Surface Side Is in Predetermined Range. JP2014004497-A.

[53] Ma, Z., et al. (2011) Circuitous Membrane Distillation System Useful in the Treatment of Wastewater and Salty or Brine Solutions, Comprises Distillation Vessel Defining Distillation Volume Having Portions, and Array of Hollow Fiber Membranes. US2011180383-A1.

[54] Cordatos, H., et al. (2011) Zero Liquid Discharge Water Treatment System for Treating e.g. Seawater, Has Membrane Distillation Unit with Membrane Wall Allowing Vapor Transmission of Distillate from Bore Side of Hollow Fiber Membrane to Shell Side of Fiber Membrane. US2011180479-A1.

[55] Chen, J. H. and Lin, Y. H. (2011) Condensing Tube, Useful as Condensing Member in Membrane Distillation, Comprises Hollow Body Having a Central Hollow Compartment, Porous Covering Layer Covering the Hollow Body, and Condensation Chamber. US2011284444-A1.

[56] Taylor, G. P. and Sengupta, A. (2014) Membrane Contactor, Useful for Membrane Distillation and Ammonia Removal from Wastewater, Comprises Cylindrical Housing or Shell Made of Pipe, and Integrally Potted Hollow Fiber Membrane Structure in Cylindrical Housing. US2014263061-A1.

[57] Francis, L., Ghaffour, N. and Alsaadi, A. (2016) Membrane Distillation Used for Desalination of Water, Involves Providing Membrane Distillation Module Which Is Submerged with Tank, Heating Feed Stream, Providing Difference in Partial Vapor Pressure and Passing Water Vapor. US2016310900-A1.

[58] Lee, S., et al. (2019) Recovering Resource Involves Feeding Raw Water to First-Stage Raw Water Tank, Supplying High-Temperature Vapor to the First-Stage Heat Exchanger, Performing Heat Exchange and Supplying the Changed Vapor to a Subsequent-Stage Heat Exchanger. US2019144309-A1. 
[59] Nagata, K. and Arai, H. (2016) Membrane Distillation Apparatus of Pure-Water Supply System, Used for Treatment of e.g. Wastewater, Has Condensation Portion for Separating Second Liquid-Phase Portion into Which Cooling Water Flows, and Second Gaseous-Phase Portion. WO2016006670-A1.

[60] Chidambaran, R., et al. (2016) Performing Volume Reduction and Concentration of Brine Useful for Preparing Purified Water Vapor, Involves Circulating First Brine in Tank, Creating Negative Pressure, Drawing Water Vapor into Pouch in Tank and Condensing into Water. WO2016172539-A1.

[61] Chen, L., Wang, H. and Yang, Q. (2017) Processing of Sweet Industrial Wastewater, by Heating Wastewater, Incinerating, Filtering in Hollow Fiber Nanofiltration Membrane to Remove Fatty Acid, Distilling, Evaporating and Concentrating to Obtain Crude Glycerol and Water. CN106495382-A.

[62] Van Medevoort, J., et al. (2013) Separation of Compound from Aqueous Feed Stream Involves Crystallizing Portion of Compound in Feed Stream by Adding Crystallizing Agent, Forming Mixture Containing Crystals and Liquid, and Carrying out Membrane Separation Process. EP2671845-A1.

[63] Nakado, Y., et al. (2014) Space Water Treatment System for Processing Waste Water in Space Station, Has Catalyst Oxidation Unit That Processes Supplied Treated Water by Catalyst Oxidation Method among First and Second Treated Water. JP2014188468-A.

[64] Kyungin, C., et al. (2016) Apparatus Used for Treating High-Temperature Wastewater, Comprises Waste Water Storage Tank, Contaminants Controlling Tank, Where Reverse Osmosis Membrane Process Collects Pure Water Passing from Reverse Performing Tank. KR2016123822-A.

[65] Shapiro, A.P. (2012) System for Performing Desalination Process Such as Distillation of Water e.g. Wastewater, Has Membrane Distillation (MD) Module Whose Latent Heat of Condensation Is Transferred Directly to Latent Heat of Vaporization. US2012048803-A1.

[66] KhayetSouhaimi, M., et al. (2015) Treating Aqueous Salt Streams Involves Chemical Treatment of Salt Stream to Temperature above Freezing Point of Aqueous Stream to Be Treated, Removing Salts, and Concentrating Aqueous Stream by Distillation Membrane. WO2015162314-A1.

[67] Ghaffour, N., et al. (2016) Forward Osmosis Membrane Distillation Module for Use in e.g. Industrial Saline Wastewater Applications, Has Forward Osmosis Draw Solution Chamber Including Inlet within Housing to Allow Membrane Distillation Feed Solution from Feed Chamber. WO2016135701-A1.

[68] Hong, S. P., et al. (2013) Separating and Recovering Dimethylformamide from Industrial Waste Water by Placing Polyamide Reverse Osmosis Membranes Serially or Parallely, Transferring Dimethylformamide Solvent to Distillation Tower and Separating and Purifying. KR2013101279-A.

[69] Bae, H., et al. (2016) Device Useful to Process Ammonia Wastewater, Comprises e.g. an Ammonia Concentration Tank to Supply Raw Water Containing Ammonia into Membrane Distillation Unit, and a Membrane Distillation Unit to Separate Raw Water into Processed Water. KR2016149699-A.

[70] Nakano, T. and Terashi, R. (2018) Processing Fluorine-Containing Water Involves Using Liquid Containing Fluorosilicic Ion, Supplying Liquid to Treat to One Side of Hydrophobic Porous Membrane to Perform Membrane Distillation to Increase Concentration of Fluorine Component. JP2018065101-A.

[71] Yu, J.T., Willman, E.J. and Sathyagal, A. (2017) Treating Effluent Waste from Ca- 
tion-Exchange Column Regeneration Cycle Involves Backwashing Exhausted Cation-Exchange Column with Backwash Water, Regenerating, Precipitating, Filtering, Recovering Membrane-Based Water, and Recirculating. US2017057854-A1.

[72] Yu, S., et al. (2018) Cleaning and Drying Membrane by Vacuum Membrane Distillation Comprises Subjecting the Wastewater to Vacuum Membrane Distillation Treatment, and Directly Washing and Drying the Membrane of the Vacuum Membrane Distillation. CN108704486-A.

[73] Govindan, P.N., et al. (2014) Cation-Sequestering Method Used for Production of Pure Water, Involves Adding Multi-Dentate Ligand to Aqueous Composition Containing Cations, Forming Non-Scaling Ionic Complex, and Reducing $\mathrm{pH}$ of Aqueous Composition. US2014263055-A1.

[74] Cates, E. L. H. (2016) Preventing Biofouling of Water Treatment Membrane Comprises Directing X-Rays into Water Treatment Membrane Module and at Luminescent Material That Is in Optical Communication with Water Treatment Membrane. US2016107126-A1.

[75] Guo, Q., et al. (2016) Direct Air-Cooling Heat Recovery and Water Treatment Device Comprises a Pretreatment Device, a Heating Cell, an Air Extracting Pump, a First Heat Exchanger, a First Stirring Device, a Boiler, a Membrane Distillation Device and a Water Pump. CN106219855-A.

[76] Guo, Z., Zhang, X., Luan, J. and Peng, H. (2018) Membrane Distillation Device for Treating High-Salt Wastewater Produced by Different Industrial Systems, Is Coupled to Heat Recovery System and Comprises Raw Water Tank, Membrane Distillation Module, Water Production Collection Device. CN108622983-A.

[77] Nakai, R. (2011) Membrane Distillation Type Water-Forming System for Purifying Waste Water Comprises Raw Water Tank, Membrane Distillation Apparatus, and Heating Apparatus. JP2011167597-A. 